\title{
International project INTERMAGNET and magnetic observatories of Russia: cooperation and progress
}

\author{
Sergey $Y$. Khomutov ${ }^{1, *}$ \\ ${ }^{1}$ Institute of Cosmophysical Research and Radio Wave Propagation FEB RAS, Paratunka, Kamchatka, \\ Russia
}

Abstract. Various aspects of international network of magnetic observatories INTERMAGNET such as standards, requirements for magnetic measurements, different status of published data, etc. are considered. Modern state of Russian segment of INTERMAGNET, its significance and contribution to global network are estimated. The features of monitoring of Earth's magnetic field at observatories Paratunka (PET), Magadan (MGD), Khabarovsk (KHB) and Cape Schmidt (CPS) of IKIR FEB RAS and prospects are presented in detail.

\section{Introduction}

The measurements by standard sensors and with standard methods at spatial distributed cites of the networks with various ranks are important part of experimental and observational base of modern science. The example of such network is IAGA network of magnetic observatories. This network was founded after International Geohysical Year and it defined the criteria of how and what magnetic measurements should be performed, how they should be to be processed and published. The registration of magnetic field variations at observatories were performed by analogue method on photo-paper. The absolute quartz declinometers and $\mathrm{H}$ magnetometers and proton magnetometers were used for absolute observations. The results of IAGA network of the observatories was database of the hourly values of magnetic total field vector supported by World Data Center system, for example, http://www.wdc.bgs.ac.uk/. The significance of these results for magnetology and geophysics in general cannot be overestimated.

During 1970-1980s instrumental base of magnetic measurements was actively developed. New digital variometers (quartz, fluxgate), absolute DIfluxes and Overhauser scalar magnetometers began to be used. New possibilities of measurement accuracy and frequency led to new requirements for installation and conditions of the using these devices and to new methods of processing and analysis of results of the measurements. The science generated new tasks which also required new approaches to the organization of regular magnetic observations (see, i.e., [1]). The need to develop new standards for magnetic measurements at observatories has become an urgent task. In the late 1980s, the basic principles and standards of the digital observatory network were formulated. The first results of such coordinated magnetic measurements between British Geological Survey and US Geological Survey were presented in 1987, at the General Assembly of the IUGG in Vancouver [2]. In fact, it was the beginning

\footnotetext{
*e-mail: Khomutov@ikir.ru

This work was supported by project NoAAAA-A17-117080110043-4
} 
of the formation of the international network of magnetic observatories INTERMAGNET International Real-time Magnetic Observatory Network [http://www.intermagnet.org/indexeng.php]

\section{INTERMAGNET}

INTERMAGNET declare free access to results of the measurements (for non-commercial goals), establishment and support of observatories in the developing countries, methodological and technical help, the development of the standards and requirements to the measurements, the data exchange protocols etc. INTERMAGNET magnetic observatory (IMO) is a scientific organization where the obligatory requirement is the absolute magnetic observations to support longtime homogeneous datasets, along with the three-components measurements. The most important task of INTERMAGNET and observatories is to prepare the final Definitive data (DD), i.e. minute values of magnetic total field vector as the extension of hourly datasets of IAGA. DD passed through a three-step checking procedure, which ensures their quality and reliability.

INTERMAGNET publishes a special Technical Reference Manual, which defines the recommended list of the observatory equipment, sets the main parameters of measurements (accuracy and frequency), defines protocols (frequency, formats) of data transmission in Geomagnetic Information Nodes (GIN). The Manual is updated periodically, the latest current version 4.6 was published in 2012 [2]. Any magnetic observatory, where the measurements are performed in accordance with the requirements of INTERMAGNET, may submit an Application for certification as INTERMAGNET Observatory (http://www.intermagnet.org/imos/apply-eng.php). The structure of INTERMAGNET includes The Executive Council and the Operations Committee with subcommittees in various areas (http://www.intermagnet.org/structops-eng.php).

Figure 1 shows the location of IMOs (state at the end of 2017), sorted by year of IMO status. Russian IMOs are marked by additional circle. We can note the considerable heterogeneity of the distribution of IMOs: IMOs are not located in the Arctic part of Russia (the Observatory "Tiksi" as IMO worked only in 1991), IMOs are poorly represented in the Antarctic and in oceans. However, there is a very dense IMOs network in Europe and a welldistributed network in North America, including the polar part of Canada. It should be noted that some observatories in developing countries have formal IMO status, but do not perform regular measurements and do not provide Definitive data. This problem is significant and has no obvious solutions yet. Some of the observatories have already lost IMO status, but they are shown in Figure 1, because their data is included in the INTERMAGNET database.

Figure 2 provides an opportunity to estimate the evolution dynamics of the INTERMAGNET. As an indicator, the cumulative number of IMOs (that is simple growth), which were accepted in INTERMAGNET in a certain year, is used. For some IMOs, mainly in the early years, the official date of gaining the IMO status is not known. In this case, the year of the first Definitive data is used. The Figure 2 also shows the number of available Definitive data by year.

The obvious feature of the plots in Figure 2 is the difference between the number of IMOs and the amount of Definitive data prepared (and publisheded) by IMOs. There is a permanent difference since the INTERMAGNET foundation. This difference has been growing since 2005, peaking in 2016 (DD for 2017 is still in preparation and checking). One of the reasons for the increase in the difference may be the difference between the total number of observatories with IMO status and actually functioning observatories: due to the newly accepted IMOs, the total number of IMOs increases, but the data are provided only by new IMOs, so the increase is not observed. 


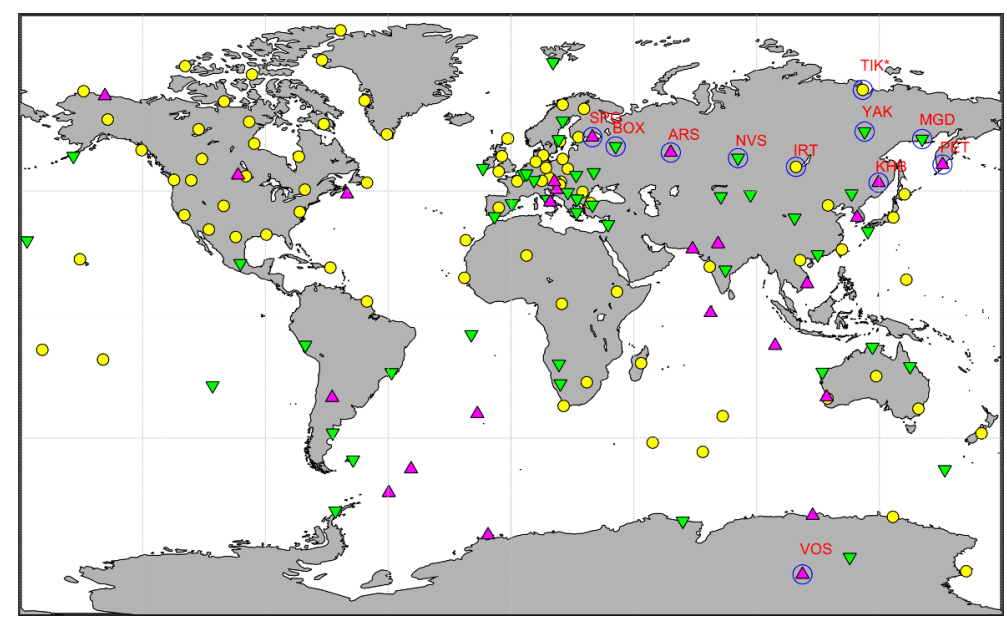

Figure 1. INTERMAGNET magnetic observatories: symbol "o" marks IMOs certified before 2000, $" \nabla "$ marks IMOs cerified during 2000-2010, symbol " $\Delta$ " marks IMOs certified after 2010. Russian observatories are marked by an additional circle. Information as at the end of 2017.

Figure 3 shows the statistics of the Definitive (final) data prepared by IMOs and published on INTERMAGNET CD, DVD, USB Flash or electronically in the INTERMAGNET databases. Data on Russian IMOs are highlighted in red. It can be seen, that the first (oldest) IMOs prepared 27 DD sets. There are IMOs that have not released any DD series. More informative estimation of the problem with the preparation of the DD can be obtained by comparing the duration of IMO status of the observatory (in years) and the number of DD prepared by it (see Figure 4).

Zero values in Figure 4 means that the observatory has prepared all the annual Definitve data since the date of IMO status. A negative value indicates that the observatory prepared Definitive data for more earlier years than the year of INTERMAGNET certification. For example, the observatory PET got IMO status in 2013, but its inner databases contained the results of earlier digital magnetic measurements and the processing of these data allowed obtaining of Definitive data since 2007. Positive values are the number of data not prepared by the observatories (the value " $+1 "$ in most cases shows that the observatory has not prepared DD for 2017). The value of +26 for TIK is the result of the case was prepared only one DD set, in 1991.

\section{Russian segment of INTERMAGNET}

After the collapse of the USSR in 1991, the financial and organizational difficulties of Russian science affected the magnetic observatories. Some observatories stopped regular measurements, some observatories continued the measurements, but the processing was not performed and the results just got into the internal archives. There has been no development of new devices, in general. Against this background, the continued development of magnetic observations at the observatory "Patrony" (Irkutsk, code IAGA is IRT) of the Institute of Solar-Terrestrial Physics SB RAS (ISTP) looked particularly striking. Thanks to the efforts of the observatory team, first of all, Stanislav Nechayev, who developed the digital quartz variation magnetometers, and the support of the international activity of Alexander Potapov, 


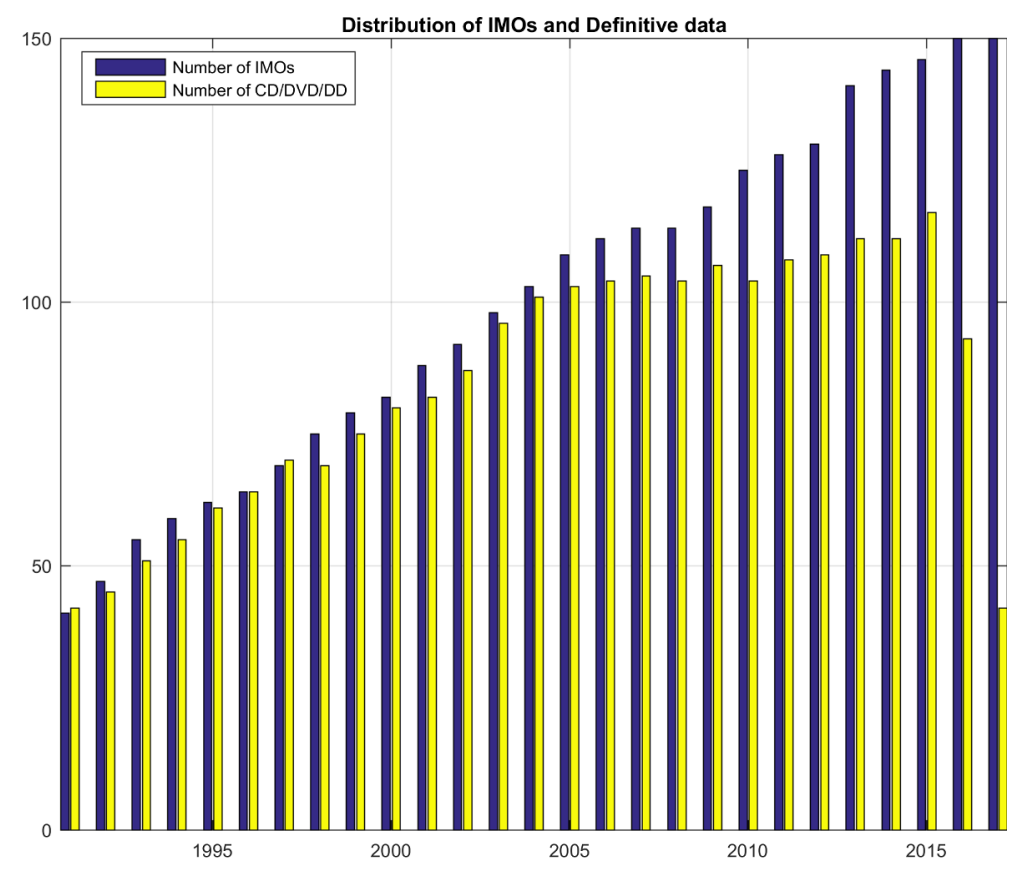

Figure 2. Dynamics of INTERMAGNET development: the number of IMOs by year (estimated by the date of applications or by the year of the first Definitive data) and the number of final IMOs yearly data presented on the INTERMAGNET CD and DVD, as well as available in electronic form (Definitive data).

the IRT was the first observatory in the CIS to obtain the status of the INTERMAGNET observatory in 1998 [3].

At the end of the 1990s, a project was prepared at the ISTP SB RAS, the main purpose of which was the modernization of the CIS magnetic observatories. The project in 1999 was presented by Aleksandr Potapov on the EXCON INTERMAGNET meeting in Budapest. The project was supported, the INTAS was proposed as a source of funding, the coordinator was Jean Rasson. The detailed elaboration and development of these proposals led to the CRENEGON project ( $C$ reation of a REnewed NEtwork of basic Geomagnetic Observatories of NIS countries), which was supported by the INTAS Foundation in 2002 and assumed a complete upgrade of the two observatories to the level of IMO, including equipment and infrastructure. During the implementation of CRENEGON more optimal use of funds allowed to modernize several CIS observatories, including the Russian observatories "Patrony" PET (Irkutsk), "Klyuchi" NVS (Novosibirsk) and "Paratunka" PET (Petropavlovsk-Kamchatsky). At the same time, the Institute de Physique du Globe, Paris, France (IPGP) modernized the observatory "Borok" BOX. The project was completed in April 2004. Details of its implementation and results are described in [4], [5]. Due to the project CRENEGON and IPGP, Russian observatories BOX and NVS began to perform the magnetic measurements in accordance with the standards of INTERMAGNET in 2003, and in 2004 their application for membership in INTERMAGNET was supported.

Regular magnetic measurements at IMOs IRT, BOX and NVS could not adequately represent changes of the magnetic field over territory of Russia, especially in the North-Eastern region. This reduced the reliability of models of the Earth's main magnetic field, which were 


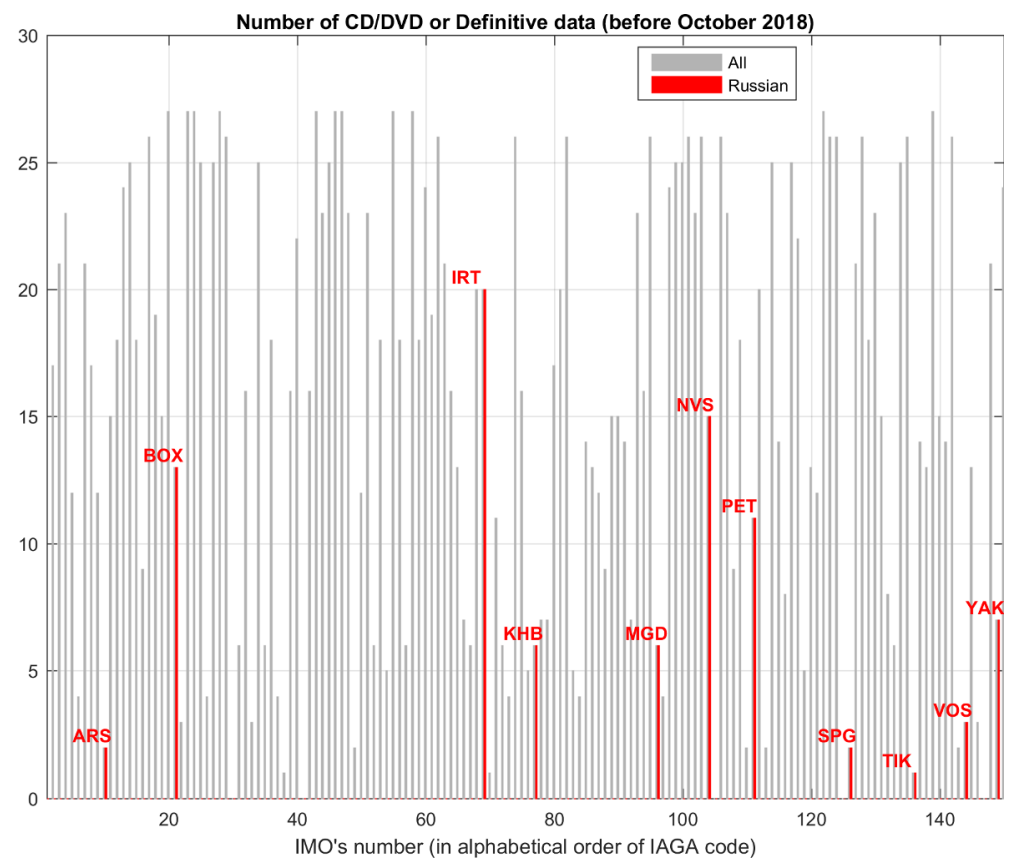

Figure 3. The number of Definitive data sets at INTERMAGNET CDs, DVDs, USB Flash and in electronic form prepared before September, 2018. The sequence number of IMOs are presented in accordance with the IMO list on INTERMAGNET website (http://www.intermagnet.org/imos/imotblobseng.php).

developed by German and British scientists. Therefore, Mioara Mandea, Head of Section 2.3 at Helmholtz Centre Potsdam - GFZ German Research Centre for Geosciences, has initiated a project for the modernization of a number of observatories of the Russian Academy of Sciences (RAS), including the observatories "Yakutsk" YAK (IKFIA SB RAS) and "Magadan" MGD and "Paratunka" PET (IKIR FEB RAS). As part of agreements between the Russian institutions and GFZ these observatories have got modern instruments: fluxgate variometers FGE-DTU, Overhauser scalar magnetometers GSM-19 and GSM-90, the absolute DIflux magnetometers Theo 020B, and staff were trained at the observatory "Niemegk" (Potsdam). The observatory MGD got the status of INTERMAGNET observatory in 2009 and the observatory YAK joined it in 2010. The observatory "Paratunka" was certified as IMO in 2013. In the same year, after modernization with the support of FEB RAS, the third observatory of IKIR FEB RAS "Khabarovsk" KHB was accepted into INTERMAGNET.

In 2011, with the support of BGS, the observatory "Arti" ARS (Institute of Geophysics UB RAS, Ekaterinburg) got the status IMO. Since that time, the technical assistance of the observatory was provided by the Geophysical Cener (GC) of RAS. In 2013, the Russian observatory "Vostok" VOS (AARI, Rosgydromet), located in Antarctica, was also certified as IMO.

Almost at the same time Geophysical center RAS (Moscow, http://www.gcras.ru/) activated the work to renew the Russian network of magnetic observatories. The RussianUkrainian Geomagnetic Data Center was created in 2012 as division of GC RAS. Its task is the collection and storage of measurement results of the magnetic observatories from Russia and Ukraine. One of the important objectives of the Center is organization of new observato- 


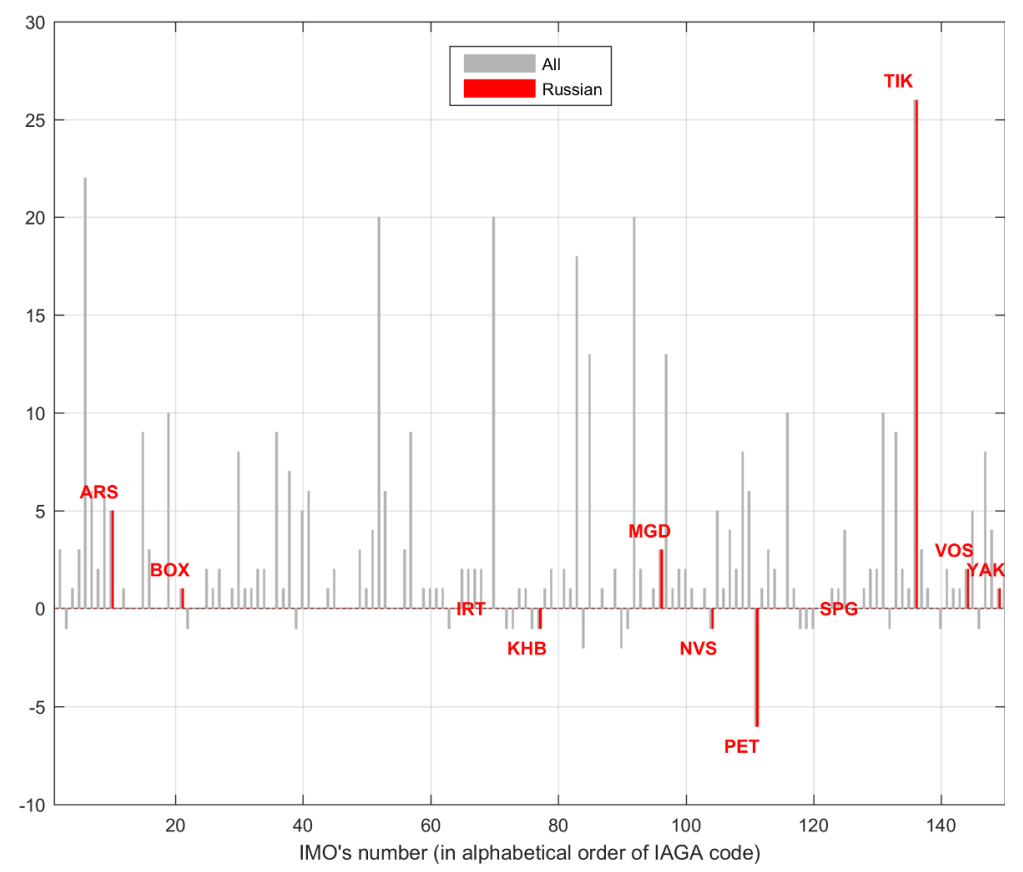

Figure 4. The difference between the duration of the work of the observatories in IMO status (in years) and the number of annual DD data produced.

ries and the upgrading of the existing observatories to the level IMO. Through the efforts of GC RAS a new magnetic observatory "Saint Petersburg" SPG was created in 2012, which in 2016 got the status of the IMO (see [6]).

Thus, at the present (September 2018) in Russia there are 10 observatories that have been certified as observatories INTERMAGNET: ARS, BOX, IRT, KHB, MGD, NVS, PET, SPG, VOS and YAK (see Figure 1). They form a mid-latitude observation network that covers evenly the territory of Russia in longitude. It can be seen that there are no observatories in the polar region. However, there are certain prospects for the development of the IMO network in high latitudes. Due to efforts of GC RAS the observatory "Klimovskaya" KLI (Arkhangelsk region, http://geomag.gcras.ru/obs-KLI.html) was created and reached the INTERMAGNET standards in 2011 [7]. Currently KLI pass the certification procedure as IMO. In addition, GC RAS organized a new magnetic station "White Sea Biological Station" BBS (Kola Peninsula, http://geomag.gcras.ru/obs-BBS.html), where measurements were began in September 2018. Observatory "Cape Schmidt" CPS (Chukotka) supported by IKIR FEB RAS and at the present time has a complete set of magnetometers for measurements according to the standards of INTERMAGNET [8]. In Norilsk a magnetic station NOK (ISTP SB RAS, http://en.iszf.irk.ru/Norilsk_Integrated_Magnetic-Ionospheric_Station) is in operation. It should also turn to magnetic measurements according to INTERMAGNET standards in the future.

The information about the magnetic field obtained by the Russian IMOs is very important for the scientific community, despite of the fact that their relative number is not large. The most important factor for many scientific and applied tasks is the spatial uniformity of the data used. Therein, the measurements on Russian IMOs are particularly valuable, for example, in the development of models of the Earth's main magnetic field, such as IGRF [9] or WMM 
[10], or for the calibration of magnetometers installed on satellites, such as the European satellite SWARM [11].

IMO status assumes that data is made available to users through the main INTERMAGNET site. Figure 5 summarizes the number of data requests from the site (http://intermagnet.org/data-donnee/download-eng.php) during May-September, 2018. The summary is given for each observatory and it is simply the number of daily files of various status (Reported/Variation, Adjusted/Provisional, Quasi-Definitive and Definitive) transferred to users during one week. Figure 5 shows the statistics for all types of files for 10 Russian IMOs and 10 selected IMOs, evenly distributed over the Earth. It is clearly seen that the number of daily files transferred during certain periods is very large and can reach several thousands. Of course, this amount of data is mainly related to requests from data servers, for example, from the WDC, but the requests of individual researchers can also be significant. For example, the data of single observatory for 5 years is almost 2000 daily files.
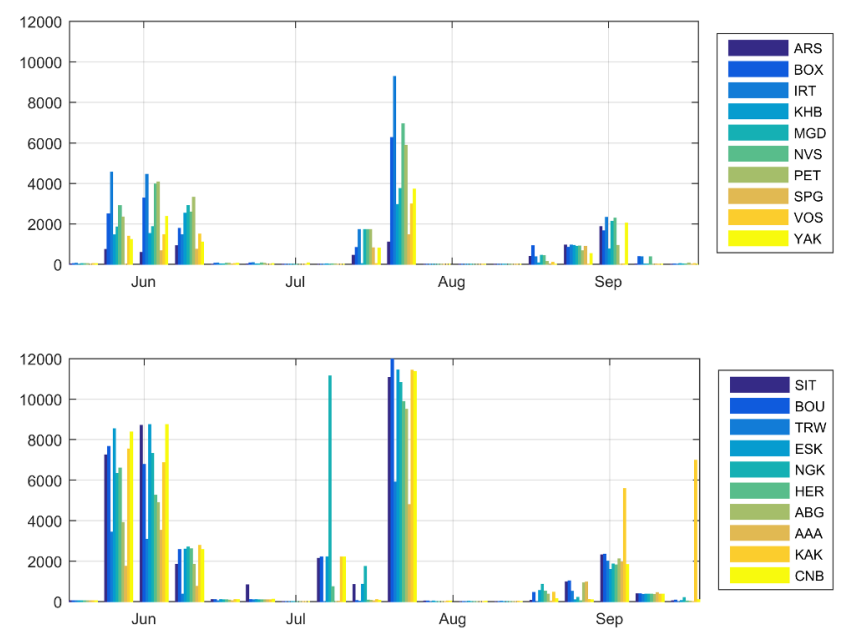

Figure 5. Summary statistic of requests of daily files during week from INTERMAGNET request form (upper panel - Russian IMOs, lower panel - IMOs, selected over world).

Comparison of the amount of information requested for the Russian IMOs is comparable with the statistics for the selected IMOs. For example, in July, data from the observatory IRT were provided for near 10 thousand days, and the most intensively interesting observatory BOU (USA) shows statistics of 12 thousand files. Of course, the observatories, which have long history in INTERMAGNET, have long datasets and scientific and applied interest in these data is higher, in general. The simplest normalization of statistics above using the total number of Definitive data (Figure 3), which is a kind of "IMO age", can significantly reduce the effect. The statistics corrected in this way is presented in Figure 6 and shows that interest in Russian IMOs data from community is significant, even compared to the world's leading observatories. 

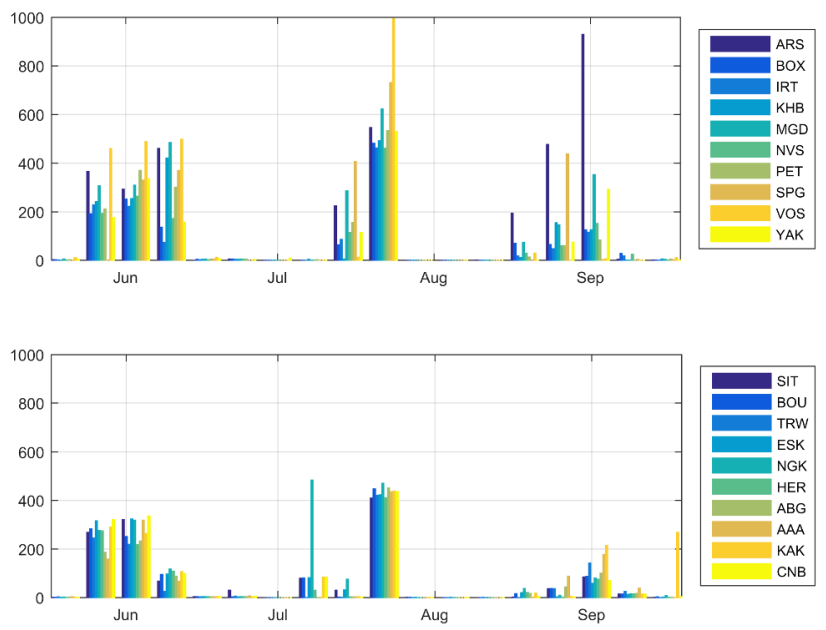

Figure 6. The same as Figure 5, but with normalizing of statistics by duration of IMOs history in INTERMAGNET status (in years).

\section{Observatories of IKIR FEB RAS}

The observatories KHB, MGD and PET of IKIR FEB RAS with IMO status and the observatory CPS cover the territory of the Far East from the southern border of Russia to the Arctic. Observatories are substentially equipped with the same type of magnetometers (dIdD GSM19FD, Mag-01H, POS-1, GSM-19 and others), use standard software and perform measurements by standard methods ([8], [12], [13]). The free exchange of results, the maintenance of a common database and the rapid exchange of information about the conditions during measurements can effectively solve the problems of magnetic monitoring and provide interchangeability in the analysis and processing of raw data.

The exchange of primary data and standardization of measurements at magnetic observatories (MO) of IKIR are a good tool for choice of the optimal parameters of magnetometers (for example, dIdD or POS-1), for identification of errors and failures in device operation, for the detection and interpretation of noise [14]. As an example of the joint processing of IKIR IMOs data, Figure 7 shows fragments of the magnetic declination D records on 24.05.2013, on which a signal from a strong earthquake with a magnitude of $\mathrm{Ms}=7.5$ is observed. The earthquake occurred at 05:44:49UT in the Okhotsk Sea. All measurements were made by magnetometers with suspended sensors (fluxgate magnetometer FGE-DTU, magnetometer with ring system dIdD GSM-19FD and quartz station "Quartz-6"), that is used to compensate tilting of the pillars. Therefore, in contrast to natural geomagnetic variations, strong response in Figure 7 is fictitious, and caused by the oscillations of suspended sensors during the seismic waves passage through the magnetometer location.

The uniqueness of the IKIR MOs network is the location of the observatories near the shelf of the Okhotsk, Chukchi and East Siberian seas, which are considered as oil and gas province. Magnetic data obtained at the MOs can be used in drilling operations and for the development of detailed magnetic maps of hydrocarbon exploration and production areas [16]. 


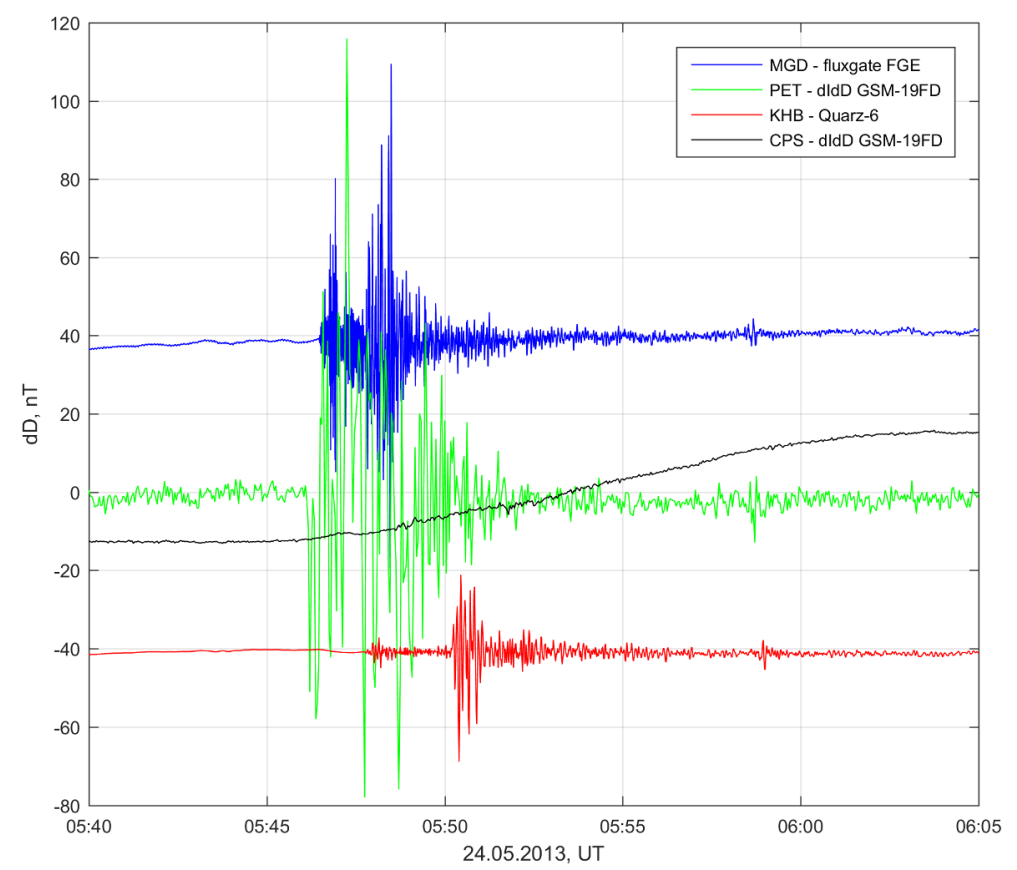

Figure 7. "Earthquake effect" in the magnetic records obtained by magnetometers with suspended sensors. Earthquake was in Okhotsk Sea at 05:44:49UT on 24.05.2018, magnitude Ms=7.5.

There is also considerable interest in the IKIR MOs data from the scientific community. Thus, a group of scientists led by O.V. Mandrikova has been actively studying the processes in the ionosphere and magnetosphere for several years, using new developed mathematical methods of data analysis. As an experimental basis, the results of measurements at the IKIR MOs are used, taking full advantage of the spatial distribution of the observatories, including mid and high latitudes (see, for example, [17] and references there).

\section{Conclusions}

Since 1991 there is global network of magnetic observatories INTERMAGNET (IMOs) with standards for magnetic measurements, data processing and transfer of results to database centers. Total number of INTERMAGNET members is about 150. Russian observatories ARS, BOX, IRT, KHB, MGD, NVS, PET, SPG, VOS and YAK are an important part of INTERMAGNET, providing the scientific community with information about the magnetic field in Russia and Antarctica. There are prospects for expanding the Russian segment of INTERMAGNET through the creation of new observatories with IMO status, primarily in the polar regions.

Magnetic observatories of IKIR FEB RAS form a network in the Russian Far East. They are equipped with similar equipment and perform measurements and processing of results according to common methods and programs. This provides an opportunity for online exchange of raw and processed data, which is important for various applied and scientific tasks, for example, for forecasting of Space Weather or seismic activity. 
Acknowledgments. The author is grateful to the staff of IKIR FEB RAS observatories that support magnetic measurements in accordance with INTERMAGNET standards.

\section{References}

[1] Thomson Alan W.P., Weather 69, 234-237 (2014), doi:10.1002/wea.2329

[2] INTERMAGNET Technical Reference Manual. Version 4.6. Edited by Benoit St-Louis (BGS, Edinburg, 2012) 92

[3] Nechaev S.A., Metrological basis Metrological basis of magnetic observations at Siberia and the Far East. Reports book of seminar, Paratunka, 11-16 August 2003 (IKIR FEB RAS, Petropavlovsk-Kamchatskiy, 2003) 10-17, in Russian

[4] Rasson J.L., Potapov A.S., Korepanov V.E., Khomutov S.Y., Krasnov V.M., Bitterly J., Earth Planets Space 58, 717-722 (2006)

[5] Potapov A.S., Khmutov S.Y., Rasson J.L., Vestn. Otd. nauk Zemle 3, NZ5005 (2011), doi:10.2205/2011NZ000107, in Russian

[6] Sidorov R., Soloviev A., Krasnoperov R., Kudin D., Grudnev A., Kopytenko Y., Kotikov A., Sergushin P., Geosci. Instrum. Method. Data Syst. 6, 473-485 (2017), https://doi.org/10.5194/gi-6-473-2017

[7] Soloviev A. A., Sidorov R.V., Krasnoperov R.I., Grudnev A.A., Khokhlov A.V., Geomagnetism and Aeronomy 56, 342-354 (2016)

[8] Babakhanov I.Y., Basalaev M.L., Dumbrava Z.F., Khomutov S.Y., Poddelsky I.N. Solar terrestrial relations and physics of earthquakes precursors: VI Intern. Conf., v. Paratunka Kamchatka region, 9-13 September 2013 : The Reports / ed. by B.M. Shevtsov (IKIR FEB RAS, Petropavlovsk-Kamchatsky, 2013) 234-238, in Russian

[9] Thebault E., Finlay C.C, Beggan C.D., Alken P., Aubert J., Barrois O., Bertrand F., Bondar T., Boness A., Brocco L., Canet E., Chambodut A., Chulliat A., Coisson P., Civet F., Du Aimin, Fournier A., Fratter I., Gillet N., Hamilton B., Hamoudi M., Hulot G., Jager T., Korte M., Kuang W., Lalanne X., Langlais B., Leger J.-M., Lesur V., Lowes F.J. et al., Earth, Planets and Space 67:79, 1-19 (2015), DOI 10.1186/s40623-015-0228-9

[10] Chulliat A., Macmillan S., Alken P., Beggan C., Nair M., Hamilton B., Woods A., Ridley V., Maus S., Thomson A., 2015, The US/UK World Magnetic Model for 20152020: Technical Report, National Geophysical Data Center (NOAA, 2015) 1-106, doi: 10.7289/V5TB14V7

[11] Finlay C.C., Olsen N., Kotsiaros S., Gillet N., Clausen L.T., Earth, Planets and Space 68:112, (2016), DOI 10.1186/s40623-016-0486-1

[12] Khomutov S.Y., J. Ind. Geophys. Union (Special Volume - 2) 2, 54-61 (2016), http://www.j-igu.in/Spl2_aiga_web files/paper8.pdf

[13] Khomutov S.Y., E3S Web of Conferences 20, N02002 (2017), DOI: 10.1051/e3sconf/20172002002

[14] Khomutov S.Y., Mandrikova O.V., Budilova E.A., Arora Kusumita, Manjula L., Geosci. Instrum. Method. Data Syst. 6, 329-343 (2017), https://doi.org/10.5194/gi-6-329-2017

[15] Khomutov S.Y. Geodynamical Processes and Natural Hazards. Lessons of Neftegorsk: International scientific conference, Yuzhno-Sakhalinsk, May 26-30, 2015.: Proceedings. In 2 Volumes / Editors: B.W. Levin, O.N. Likhacheva, Vol. 2 (Dal'nauka, Vladivostok, 2015) 173-176, in Russian

[16] Gvishiani A.D., Lukianova R.Yu., Izvestiya, Physics of the Solid Earth 54, 554-564 (2018) 
[17] Mandrikova O.V., Solovyev I.S., Khomutov S.Y., Geppener V.V., Klionskiy D.M., Bogachev M.I., Ann. Geophys. 36, 1207-1225 (2018), https://doi.org/10.5194/angeo-361207-2018 